\title{
High-Resolution Mapping Using a Sub-Audio Magnetic Survey at the Comet Gold Mine, Western Australia
}

\author{
Piyaphong Chenrai ${ }^{1,2}$, Jayson Meyers ${ }^{2}$, and Punya Charusiri ${ }^{1, *}$ \\ ${ }^{1}$ Department of Geology, Faculty of Science, Chulalongkorn University, Bangkok, Thailand \\ ${ }^{2}$ Department of Exploration Geophysics and CRC-LEME, Curtin University of Technology, Perth, Australia
}

Received 30 March 2010, accepted 30 March 2011

\begin{abstract}
The Comet Gold Mine in the Murchison mineral field lies within the Yilgarn Craton of Western Australia. Gold mineralization in this area is associated with a series of north-northeasterly trending structures, and has a long exploration history with some previous geophysical information. Other exploration information, such as geology and drill hole data, are integrated with the geophysical results to study the geophysical responses and generate a geophysical interpretation map. The response from the sub-audio magnetic (SAM) survey was investigated over an area of $13 \mathrm{sq} \mathrm{km}$. The SAM survey was completed using a transmitter current of 5 - 8 Amp with a 50\% duty cycle at $4 \mathrm{~Hz}$ frequency, which was considered a good instrumental setting for the Comet area. SAM anomalies were compared to results obtained from other geophysical methods and then integrated with geological data to generate a geophysical interpretation map at a $1: 5000$ scale. The new interpretation of geological units and structures at the Comet area should provide a better understanding of the geological and structural setting for mineralization in the Comet area. Our results show that the Comet Fault represents a faulted limb of the Comet fold structure that has both limbs dipping to the southeast and a plunge to the northeast. Magnetic anomalies associated with sedimentary iron formation (SIF) are considered to be well correlated with some gold bearing horizons and the location of the Comet Fault, which has become more siliceous and has been altered by sulphide minerals and magnetite minerals.
\end{abstract}

Key words: Sub-audio magnetics, SAM, Gold, Comet Mine

Citation: Chenrai, P., J. Meyers, and P. Charusiri, 2011: High-resolution mapping using a sub-audio magnetic survey at the Comet Gold Mine, Western Australia. Terr. Atmos. Ocean. Sci., 22, 393-401, doi: 10.3319/TAO.2011.03.30.01(TT)

\section{INTRODUCTION}

The Comet Gold Mine, situated in the Murchison mineral field, lies within the Yilgarn Craton of Western Australia in Archaean mafic and sedimentary host rocks surrounded by granite intrusions (Smith 1998). It is located 20 kilometers southeast of the town of Cue and 60 kilometers north-northeast of Mount Magnet in the Cue and Day Dawn districts of the Murchison mineral field (Fig. 1).

The Comet gold deposit has an average grade of $6.1 \mathrm{~g} \mathrm{t}^{-1}$ gold and a total gold endowment of about 24 tons. It is hosted by banded iron formations (also referred to locally as a sedimentary iron formation, SIF) and other iron rich rocks that are surrounded by mafic rocks, porphyry and granite (Watkins and Hickman 1990; Smith 1998). Hidden

\footnotetext{
* Corresponding author

E-mail: cpunya@chula.ac.th
}

ore bodies at Comet were discovered in 1976 through a combination of geophysical and geochemical studies in the area (Smith 1998).

The discovery of gold deposits in Western Australia resulted from the application of basic geology, geochemistry and geophysics. Subsequently, to improve the interpretation of gold mineralization and hence the targeting of the area for mining, the data resolution of geophysical surveys needs to be increased. Fortunately, high-quality surveys of large areas have become available at a reasonable cost (Stanley et al. 2005).

Several different geophysical methods were used in this study to define the geophysical signatures of SIF and altered basalts that are associated with gold mineralization. The geophysical surveys carried out at the Comet Gold Mine were sub-audio magnetic (SAM), aeromagnetic and gravity. Earlier work has shown fairly conclusively that the 
SAM approach can be applied successfully to delineate and quantitatively interpret lineaments related to sulphide deposits (Cattach and Boggs 2005). The main aim of this study was to generate an understanding of the various geophysical responses of geology and gold mineralization in the Comet Mine area for future gold exploration in this region. In particular, this study focused on the ability of the SAM method to map out the geology and geophysical response.

\section{GEOLOGICAL SETTING}

The Comet Gold Mine, situated in the Archaean Yilgarn Craton of Western Australia, is composed almost entirely of granite-greenstone terrains. A significant portion of the exposed greenstone belt covers about $30-40 \%$ of the study area. Almost all the known gold deposits in this region are temporally and spatially associated with the greenstone belts and small granitoid plutons at the margins of the greenstone belts. The Yilgarn Craton appears to have been assembled between $\sim 3.00$ and $2.60 \mathrm{Ga}$ by the accretion of a multitude of formerly present blocks or terranes of existing continental crust (Myers 1993).

The greenstone sequence exposed at the Comet Mine forms part of the Moyagee Formation, the lowest sequence

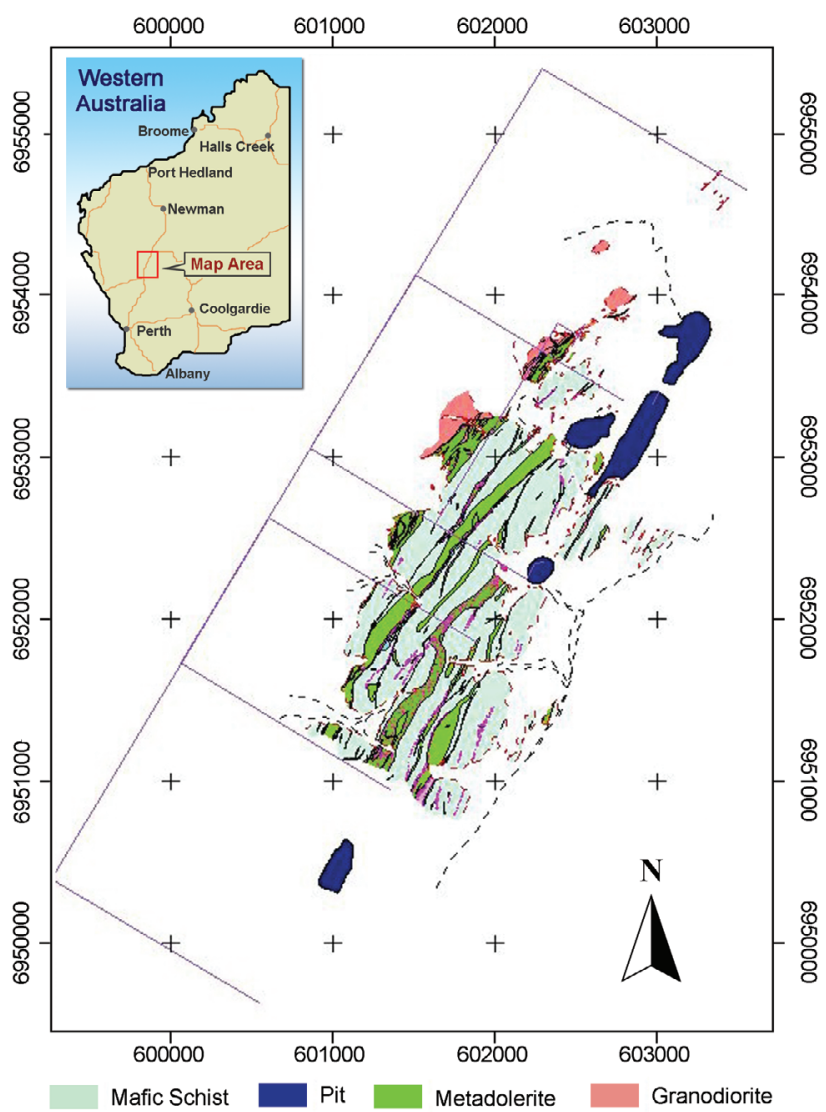

Fig. 1. Location of the project area with regional geology near Cue, Western Australia with SAM current electrode in purple lines. of the Archaean stratigraphy in the Murchison Province (McIntosh and Guj 1982). This formation consists largely of mafic and ultramafic volcanic and plutonic rocks, and siliceous rocks including SIF to cherts with minor clastic sediments as black shales.

The regolith of Yilgarn Craton is usually represented by deep weathering rocks. In some areas, the bedrock has been completely converted to saprolite at up to $100 \mathrm{~m}$ depth from the surface. However, there is very little to no regolith cover in the Comet Mine area, where most of the area shows exposed fresh bedrock.

The study area is located to the west of the southern end of the Tuckabianna Shear Zone, a 1 - $2 \mathrm{~km}$ wide, northnortheast trending zone of over $30 \mathrm{~km}$ length (Fig. 1). The shear zone has been interpreted as being part of the 180-km long Mt. Magnet-Meekatharra Shear Zone. Although an alternative interpretation is that this shear zone is, in fact, a series of splay faults off from the regional Moyagee Shear located to the west.

It is important to note that gold mineralization is associated with a series of regional dominant, north-northeasterly trending parallel structures. Also, gold mineralization is usually associated with variable amounts of pyrrhotite and pyrite that can range from disseminated to semi-massive, and with highly sulphide rich fractions of SIF within highly foliated metabasalts (Jordan 1987). Chalcopyrite was also reported to occur in minor amounts (McIntosh and Guj 1982; Lane et al. 1999). However, gold was also reported to be produced from laterite and alluvial deposits at Tuckabianna (Smith 1998).

The principle of geophysical interpretation is subject to individual styles. It is important to remember the wide range of magnetic responses corresponding with the wide range of geophysical environments where magnetic responses can be usefully employed for defining geological structure based on the difference in the magnetic property of the rocks. The straightforward electrical geophysical survey is used to detect the conductive layer or mineralization associated with conductive mineral. A common method for geological interpretation is to draw geophysical features, including linear trends or circular features and is used here.

\section{SUB-AUDIO MAGNETICS (SAM)}

SAM is a galvanic geophysical survey system that injects electrical current from a generator into the ground through distant electrodes placed along the strike of the structure or lithology under investigation (Cattach et al. 1993; Jackson 2005). SAM is a high-resolution technique that combines the acquisition of magnetic and resistivity data that can aid in the geological mapping of gold prospects and the definition of targets for drilling exploration. The applied current is created with a high-power transmitter producing a time-varying square-wave signal at a sub-audio 
frequency between 1 and $8 \mathrm{~Hz}$ and at a 50\% duty cycle. Current channeling is then detected using the magnetrometric response (Cattach et al. 1993). SAM parameters are measured at meter or sub-meter intervals along the survey lines and include total magnetic intensity (TMI), total field magnetometric resistivity (TFMMR), total field magnetometric induced polarization (TFMMIP) and total field electromagnetic response (TFEM). These SAM measured parameters are then reduced to the standardized equivalent parameters as EQMMR and EQMMIP (equivalent magnetometric resistivity and equivalent magnetometric induced polarization) (Boggs et al. 1999).

Generally, the SAM survey requires laying out a wire electrode pair surrounding the research area then passing a current from a transmitter, typically $5-8$ Amps, $50 \%$ duty cycle at $4 \mathrm{~Hz}$ frequency ("sub-audio"), through the electrodes in a direction parallel to the geological strike. The Comet area was covered by the SAM survey using three large grids, and these were later merged to avoid the effect of a large ground resistance and that from the wire that was used in the survey. For each grid, a line spacing of $50 \mathrm{~m}$ was used along the northwest-southeast lying survey lines.

In this study, the TMI data derived from the SAM data were able to map out the Comet Fault, which displays a discontinuous northeast-southwest magnetic trend with a southeast dip direction where the fault follows the fold limb that dissects the southeast side of the fold (Fig. 2). Almost all open cut pits are located along high magnetic anomaly trends. The TMI data has a greater near-surface resolution than the aeromagnetic survey does, but there are also nearsurface noise sources that are then removed by the upward continuation filtering. There is a high magnetic trend in the middle of the project area with a northeast-southwest direction. This strong magnetic signature is herein interpreted to be the Comet Fault. The open cut pits may not actually be located over high magnetic anomaly trend, but in the Comet Mine are gold mineralization seems to be associated with the Comet Fault and particularly sulphide minerals. The high magnetic response seen in the TMI is in response to the SIF controlled by the regional structure. The data can be (a)

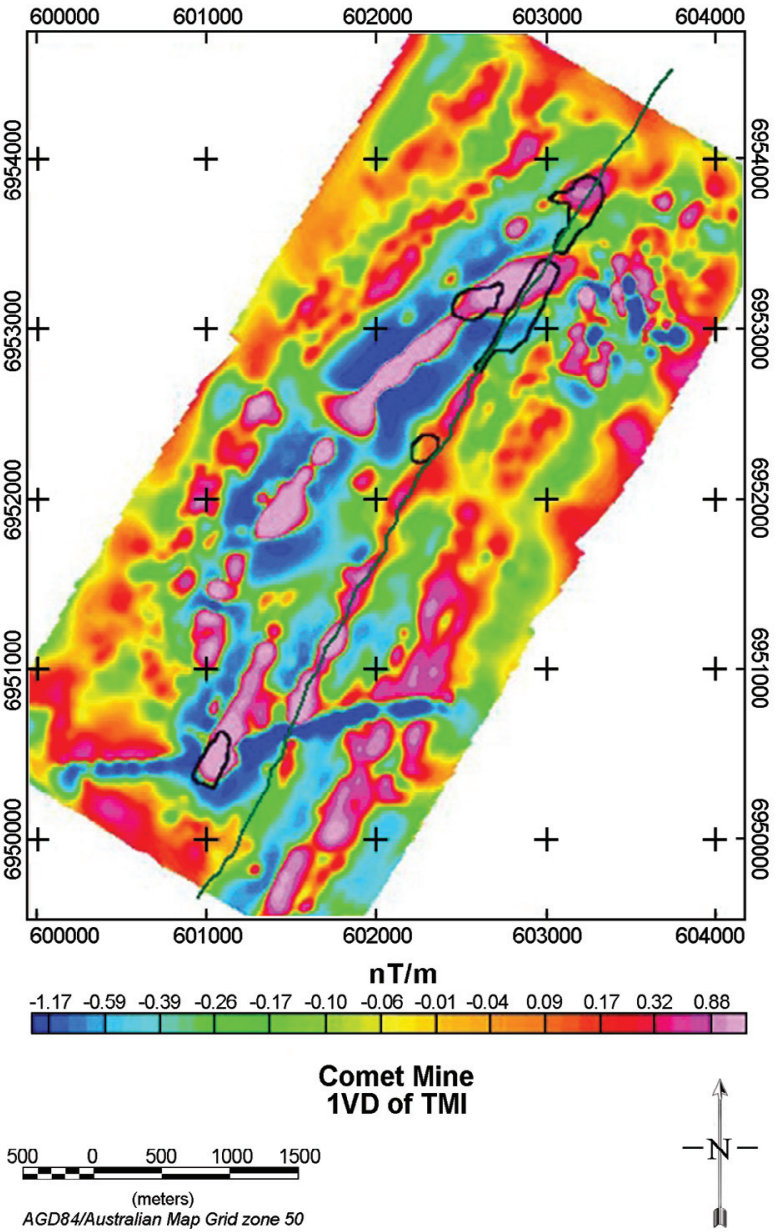

(b)

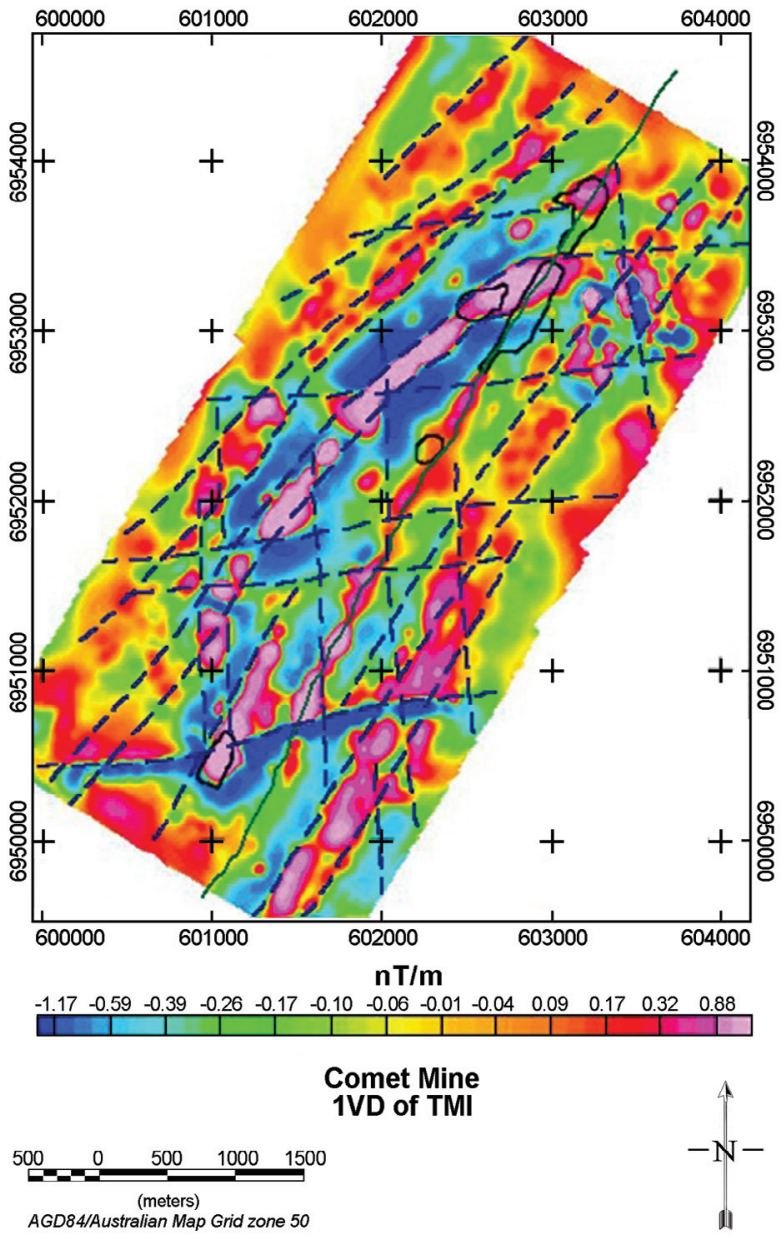

Fig. 2. (a) First vertical derivative image of the total magnetic intensity from the SAM survey, after reduction to pole and $50 \mathrm{~m}$ upward continuation filtering, with outlines of the gold mineralised areas shown in thick black lines and the Comet Fault in a green line, and (b) with linear interpretation. 
considered to be of good quality and can map out the linear trends. These trends are interpreted to be fault and geological contact.

The electrical responses in the EQMMR and EQMMIP, derived from the SAM data and shown in Figs. 3 and 4 , respectively, show a good agreement in defining the conductive and chargeable areas affected by alteration, especially along the Comet Fault, fold limbs and other shear zones. The EQMMIP and EQMMR are based on the basis of changing material around this area, which are shown as a color change in Figs. 3 and 4. Thus, a different color of EQMMIP and EQMMR represent varying degrees of current density in the ground.

The dominant response in the EQMMR image was associated with the Comet Fault. The transmitting current electrodes were placed close to the Comet Fault so the current flowed along the Comet Fault as expected. The linear trends of fault and geological contact were drawn on the EQMMR map (Fig. 3). The simplified EQMMR response compared to the TMI indicates that the main EQMMR response is proximal to the Comet Fault and fault shear zone.
The first vertical derivative of the EQMMIP data exhibits a high chargeability over not only the Comet Fault and other shear zones but also over the black shale unit in the southeastern part of the survey area (e.g., Fig. 4). It is quite likely that the gold deposits in the Comet group are associated with conductive and chargeable layers that are easily detected by SAM. A high EQMMIP response is observed at the western part of the Comet Fault, and is interpreted as fold limbs and other shear zones. The EQMMIP response seems to flow along the geological unit rather than the structure. Thus, the linear trends of EQMMIP are probable along the geological contact, with minor trends along the fault.

The interpretation of the difference between EQMMIP and EQMMR is difficult due to the existence of very little (published) information on the interpretation of SAM surveys. It is necessary to consider the geological data to interpret the SAM results. The conductivity (EQMMR) is considered to flow where alteration and deep weathering occur (weak zone) as along the fault plane. Whist, the chargeability (EQMMIP) is considered to be a flow along (a)

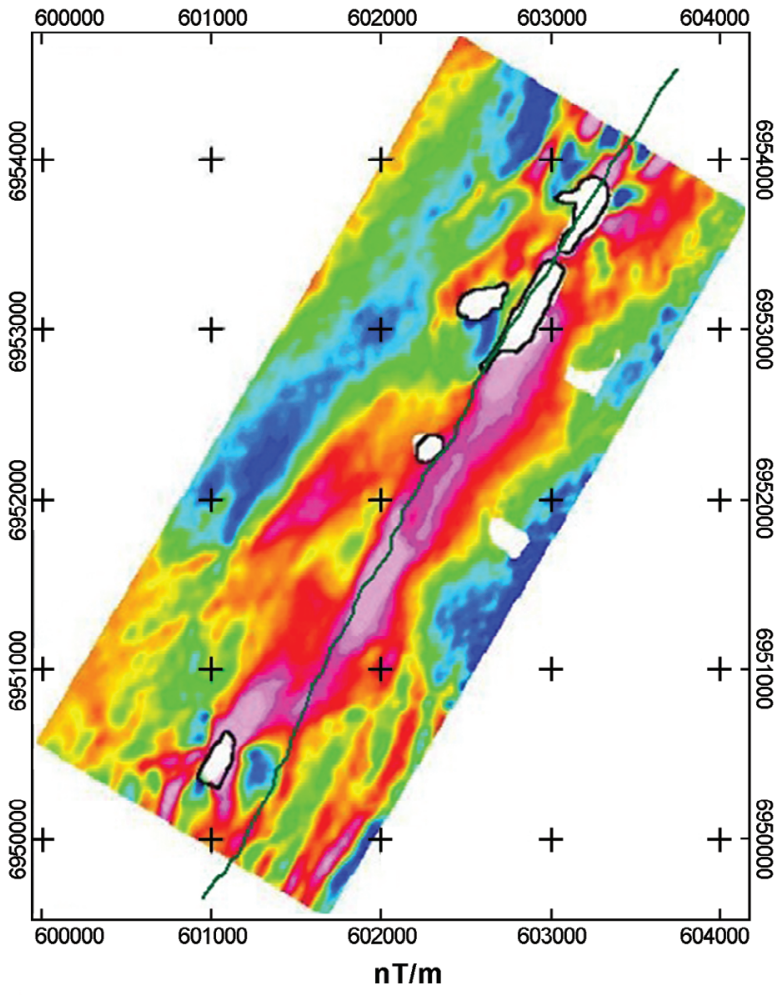

$\begin{array}{lllllllllllll}-0.21 & -0.15 & -0.12 & -0.09 & -0.07 & -0.04 & -0.02 & 0.01 & 0.03 & 0.06 & 0.11 & 0.17 & 0.27\end{array}$

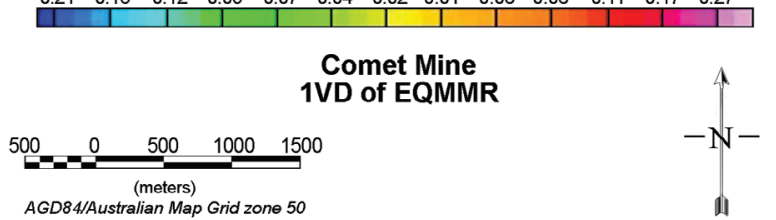

(b)

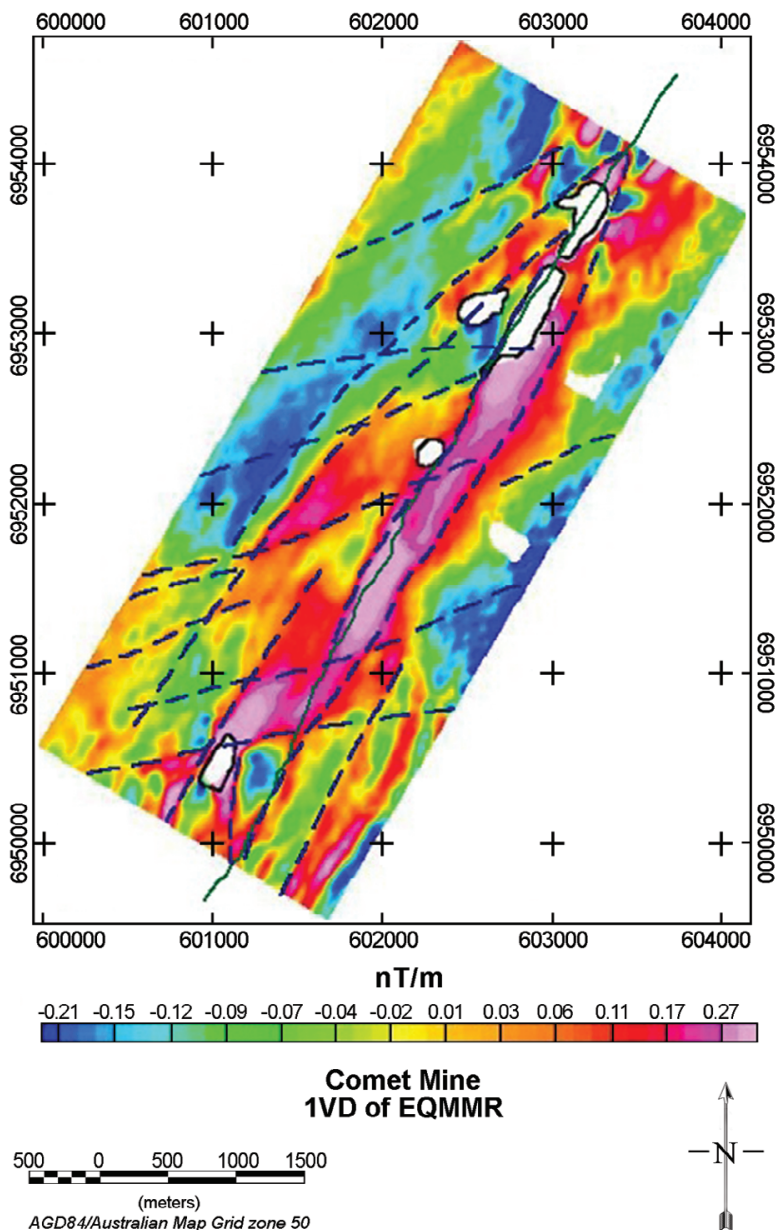

Fig. 3. (a) EQMMR image from the SAM survey after the first vertical derivative filtering, with outlines of the gold mineralised areas shown in thick black lines and the Comet Fault in a green line, and (b) with linear interpretation. 
the same geological unit rather than the weak zone.

Subsequently, the EQMMR and EQMMIP data provide an anomalous response over the Comet Fault and other parts of the deformation structure where gold mineralization commonly occurs. The SAM conductivity and chargeability current is assumed to be flowing everywhere through the ground, but to be primarily in the direction of the current electrodes (e.g., Whitford et al. 2005). The change in current density along the Comet Fault plane may be caused by the changes in the level of alteration over the mineralized system, and/or pinching and swelling of the SIF unit (see Figs. 3 and 4).

\section{AEROMAGNETICS}

The Comet Mine area was flown over by UTS Geophysics in December 1997 and evaluated using a Scintrex Cesium Vapour CS-2 total field magnetometer with a sample interval of about $10 \mathrm{~m}$ and a line spacing of $50 \mathrm{~m}$. Interpretation of the aeromagnetic data can effectively map the major fault and shears extending in a northeast-southwest direction (Fig. 5), and also highlight known magnetic mafic to ultramafic units and indicate probable SIF units and their boundaries. In addition, the magnetic features for the Comet Fault clearly show a dip to the southeast, as revealed by the asymmetry in the anomaly shape.

Thus, the aeromagnetic data provided additional lithological and structural information for the project area, but failed to map out small-scale features known to control gold mineralization. Used alone the method is not suitable but will compliment other SAM approaches.

\section{GRAVITY}

A gravity survey was completed over the project area immediately after the SAM survey. Unfortunately, the gravity survey only partially covers some part of the SAM survey area. Gravity data were collected along four transects, $500 \mathrm{~m}$ apart at a $50 \mathrm{~m}$ station spacing. The Bouguer gravity was calculated using a density at $2.67 \mathrm{t} \mathrm{m}^{-3}$, whilst the residual gravity data were created by upward continuing the Bouger gravity by $200 \mathrm{~m}$ and then subtracting this from (a)
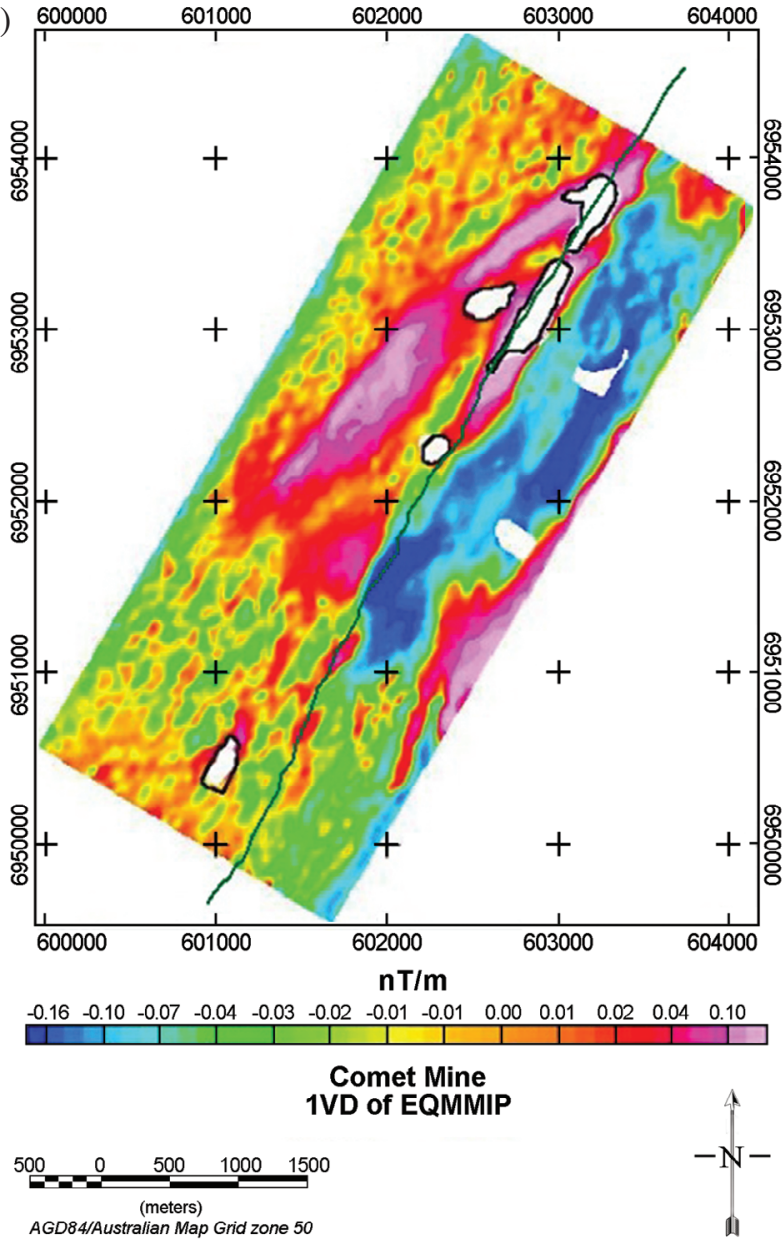

(b)

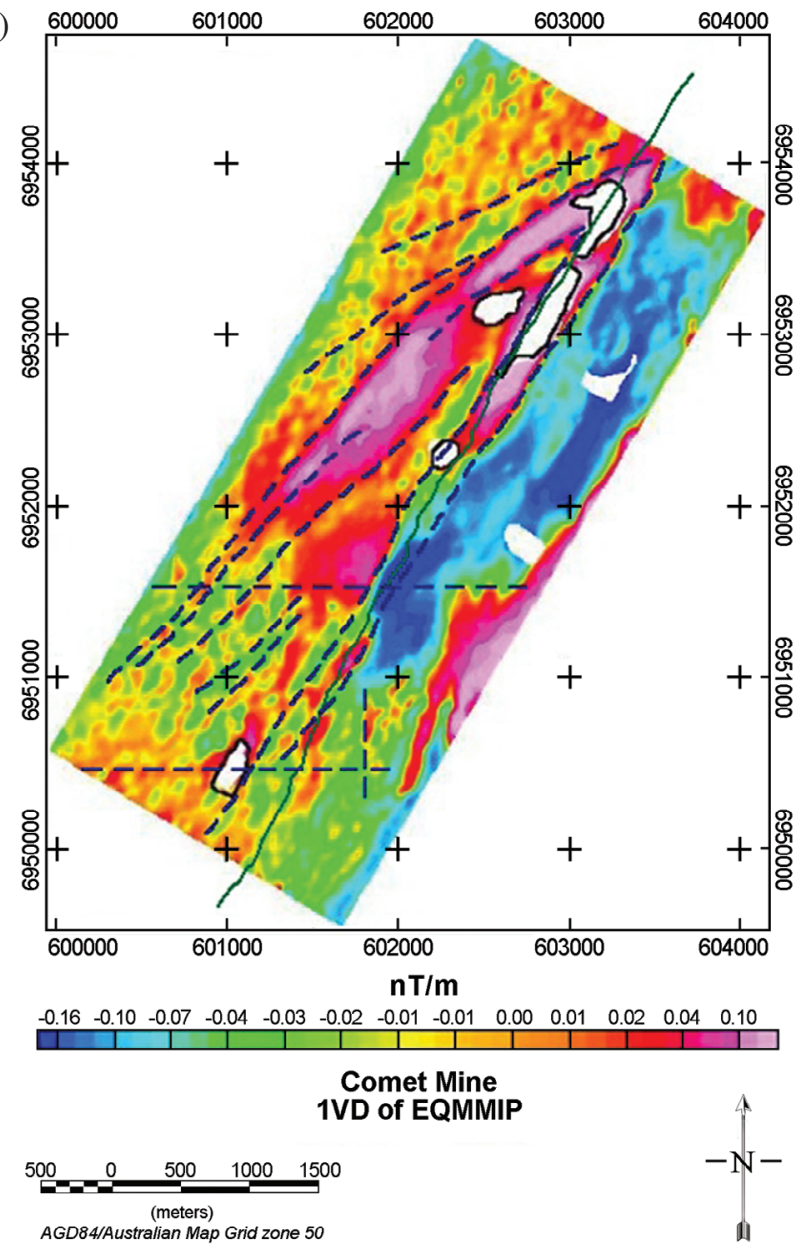

Fig. 4. (a) EQMMIP image from the SAM survey after the first vertical derivative filtering, with outlines of the gold mineralised areas shown in thick black lines and the Comet Fault in a green line, and (b) with linear interpretation. 


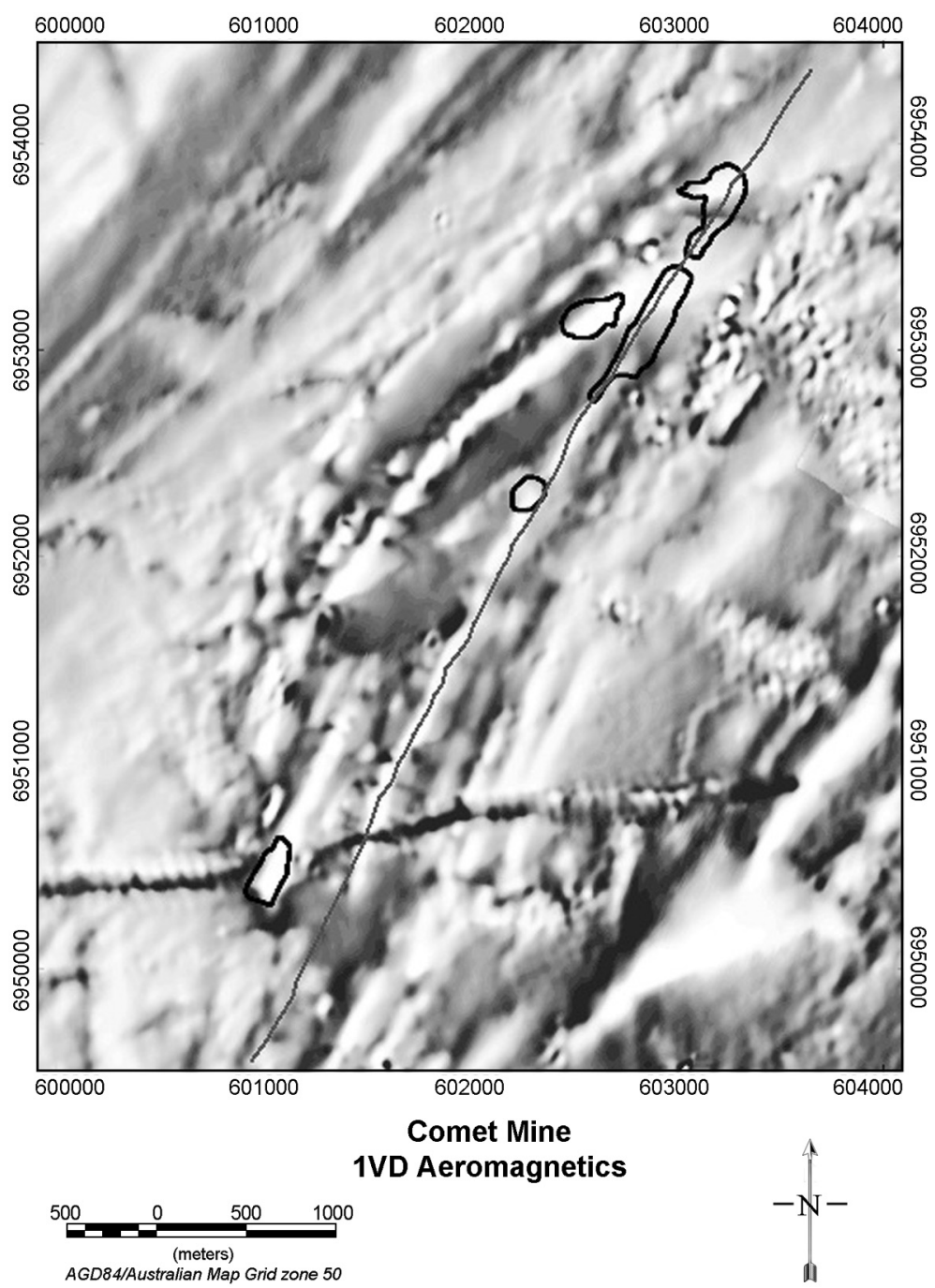

Fig. 5. The first vertical derivative image of the aeromagnetic survey after reduction to pole filtering with outlines of the gold mineralised areas shown in thick black lines and the Comet Fault in a green line.

the normal Bouguer corrected gravity data, as presented in Fig. 6. The result of the gravity survey provided felsic and mafic rock units having dips mainly to the southeast. The felsic rocks were characterized by low gravity values, while the mafic rocks were characterized by high gravity values. The data was also able to reveal the northeast-southwest trend in the rock units running parallel to the main trend related to the SIF and the basalt units. A circular gravity low (about $500 \mathrm{~m}$ in diameter) in the centre of the survey area is likely to be a deep internal granite intrusion. Therefore, gravity data can be used to map out regional intrusive bodies. There is no direct correlation between gravity data and gold mineralization.

\section{DISCUSSION}

The linear features of all geophysical survey data included in this study can be determined from the results shown in the individual maps. For the most reliable result, only one type of geophysical survey data is inadequate for interpreting the geological map. Integration and correlation of the geological, geophysical and satellite datasets can be used for establishing a much more reliable exploration map. Therefore, aeromagnetic and gravity survey data were added in this study in order to create a more complete geological map. By obtaining various geophysical survey data types, the characteristics of particular rock type locations and geometries of geological structures can be determined and used to provide geological interpretation for presenting a more reliable and higher resolution map. Such synergic contributions of these datasets are shown in Fig. 7.

The Proterozoic dolerite dyke exhibits a reverse magnetic anomaly and lies in an east-northeasterly direction. The dyke appears to be unrelated with gold mineralisation in the Comet mine. An intrusive granitic body is shown as a circular shape at the middle of the interpretation map of 
Fig. 7. This interpretation has been invaluable for identifying the bedrock geology in relation to gold mineralisation. It is quite likely, as shown in Fig. 7, that the mineralisation zones are closely related spatially to the Comet Fault and there is also a close correlation between all the mineralisation zones and SIF. The gold mineralisation in the Comet mine is consistent with earlier work reporting that the gold mineralisation is associated with northeast trending structures and SIF, typically at the intersection of two linear magnetic corridors. The Comet Fault and SIF units show strongly linear magnetic trends. This can be explained by the fact that magnetite in the SIF is formed during deposition of sediments, and additional magnetite is deposited during mineralization events. The depositional event of rock formation is described on the basis of the physical property of the rock or the formation. The SIF is characterized by a high magnetic anomaly. Therefore, the SIF is interpreted to have iron-oxide-minerals and especially magnetite, a common and a highly magnetic mineral. An important point to note here is that the accumulation of mineral deposits in the sediment layer can be increased during deformational events, such as faults, folds or mineralization.
It should be noted that the conductivity zone of the first vertical derivative of EQMMR image (Fig. 3) is different from the first vertical derivative of EQMMIP image (Fig. 4), especially over the Comet Fault in the middle of the area, while the EQMMIP shows a high chargeable zone running from the Comet Fault in the upper part of the study area. However, on a broad scale, the EQMMR and EQMMIP data provide an anomaly response over the Comet Fault and other parts of the fold structure where gold mineralization commonly occurs. In addition, the Comet Fault represents a faulted limb of the Comet fold structure that has both limbs dipping to the southeast, and plunges to the northeast.

The interpretation map (Fig. 7) provides a better understanding about the geological environment of mineralisation in the Comet area. At Comet, the gold mineralization zones are expected to be strongly conductive and/or magnetic, depending on the percentage of associated sulphide minerals and iron oxide minerals.

\section{CONCLUSIONS}

The SAM survey at the Comet Gold Mine produced

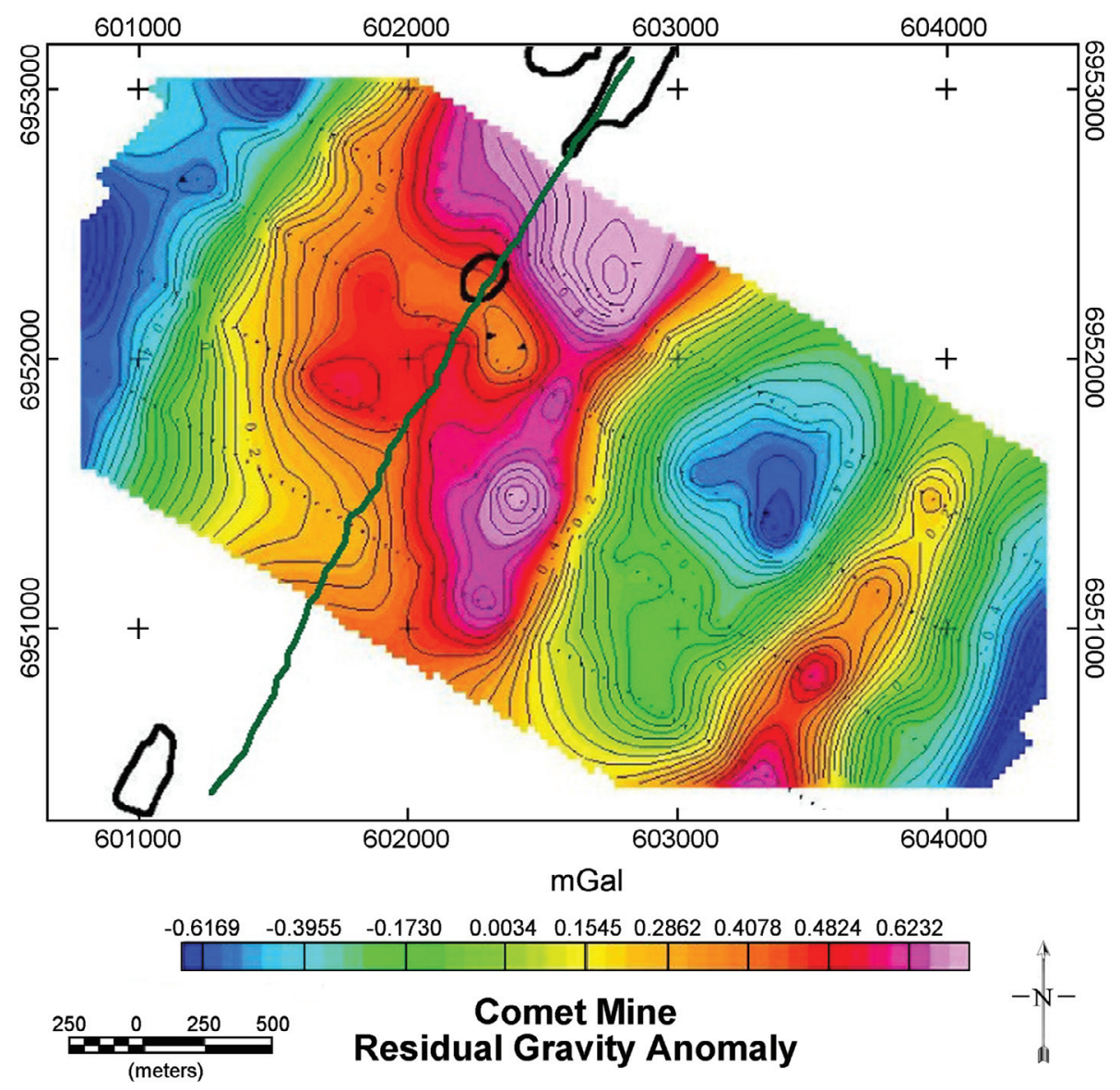

Fig. 6. An image of the residual gravity anomaly map at the Comet mine with outlines of the gold mineralised areas shown in thick black lines and the Comet Fault in a green line. 


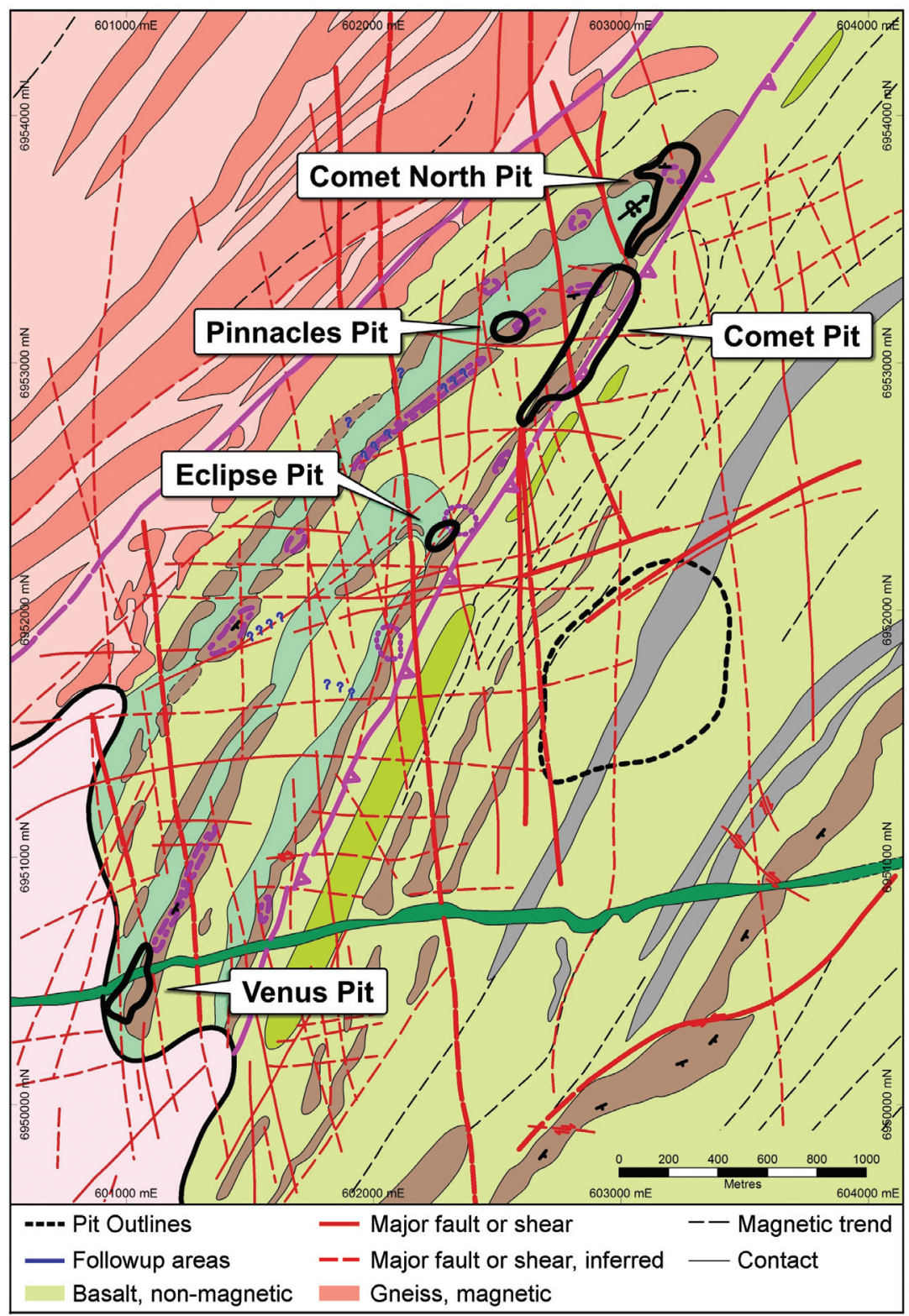

Fig. 7. Combined geophysical and geological interpretation map of the Comet Mine area.

EQMMR and EQMMIP responses that can be correlated closely with areas of known gold mineralization, and highlighted possible extensions of these zones. Although the SAM survey has not been successfully used for the direct detection of the intensity of gold mineralization at Comet Mine, the conductive response has been used to locate SIF zones, sulphide alteration zones in the basalt, and black shale in addition to delineating faults and other structures with a high degree of confidence. The area of high magnetic and electrical responses (EQMMR and/or EQMMIP) is considered to be a potential gold deposit area. This response is related to the sulphide and magnetic rich ore zones. In addition, these potential areas are interpreted to be associated with the major fault in this area. The SAM survey has also proven to be cost-effective for this type of exploration by targeting mineralized structures in detail.

The aeromagnetic, SAM and gravity data were all used together to generate a new geological and structural interpretation of the area. There is one main northeast-southwest trending structure through the central part of the survey area. This trend is closely associated with known gold mineralization in the Comet area. The subsequent interpretation of all geophysical survey data effectively mapped the major fault and shear extending from the major fault. It highlighted known magnetic SIF units, and indicated probable lithological boundaries of mafic host rocks and granitic units and a Proterozoic dolerite dyke that exhibits as a reverse magnetic anomaly. As the rocks retain the magnetic parameters 
of the Earth's magnetic field in the age in which they were formed, it can be concluded that the Earth's magnetic field sometimes switches poles. Each technical survey revealed different and complimentary information interpretation. U1timately, the SAM survey was the primary method for mapping out prospective areas for gold exploration or structural geology at a detailed mine-level scale.

Acknowledgements We thank Sunti Pailoplee and Teerarat Pailoplee for critical discussion, and Wiphawan Purisa for manuscript preparation. Parts of this project were founded by research grants to PC and JM. The Department of Geology, Chulalongkorn University, is thanked for providing all the facilities, and the Curtin University of Technology is acknowledged for allowing PC the use of all the computer and audio visuals.

\section{REFERENCES}

Boggs, D. B., J. M. Stanley, and M. K. Cattach, 1999: Three-dimensional numerical modeling of Sub-Audio Magnetic data. Explor. Geophys., 30, 147-156, doi: 10. 1071/EG999147. [Link]

Cattach, M. and D. Boggs, 2005: A Sub-Audio Magnetics case study: Flying Doctor Pb-Zn-Ag Deposit, Broken Hill, Australia. Explor. Geophys., 36, 119-124, doi: 10. 1071/EG05119. [Link]

Cattach, M. K., J. M. Stanley, S. J. Lee, and G. W. Boyd, 1993: Sub-Audio Magnetics (SAM) - A high resolution technique for simultaneously mapping electrical and magnetic properties. Explor. Geophys., 24, 384400, doi: 10.1071/EG993387. [Link]

Jackson, J., 2005: The use of Sub-Audio Magnetics (SAM) in gold exploration - Examples from the Yilgarn Cra- ton, WA. Explor. Geophys., 36, 163-169, doi: 10.1071/ EG05163. [Link]

Jordan, J. E., 1987: An appraisal of the Pinnacles prospect, 113, Murchison Mineral field W.A. Western Australian Mineral Exploration database (WAMEX) Exploration Report, 156 pp.

Lane, R., P. Leeming, M. Owers, and D. Triggs, 1999: Undercover assignment for TEMPEST. Preview, 82, 1721.

McIntosh, D. and P. Guj, 1982: The Pinnacles gold prospect: Day Dawn district - Murchison goldfield Western Australia. Western Australian Mineral Exploration database (WAMEX) Exploration Report, 23 pp.

Myers, J. S., 1993: Precambrian history of the West Australian Craton and adjacent orogens. Annu. Rev. Earth Planet. Sci., 21, 453-485, doi: 10.1146/annurev.ea.21. 050193.002321. [Link]

Smith, M. E., 1998: Tuckabianna gold deposits. In: Berkman, D. A. and D. H. Mackenzie, (Eds.), Geology of Australia and Papua New Guinean mineral deposits, The Australian Institute of Mining and Metallurgy, 149 -154 .

Stanley, J. M., M. K. Cattach, S. M. Griffin, and J. A. Townsend, 2005: Environmental applications of SubAudio Magnetics. Explor. Geophys., 36, 198-205, doi: 10.1071/EG05198. [Link]

Watkins, K. P. and A. H. Hickman, 1990: Geological Evolution and Mineralization of the Murchison Province, Western Australia, Bulletin/Geological Survey of Western Australia, 267 pp.

Whitford, M., J. Meyers, and N. Stolz, 2005: The SAM EQMMR response of the regolith at East Victory, St Ives Gold Mine, Western Australia. Explor. Geophys., 36, 133-139, doi: 10.1071/EG05133. [Link] 